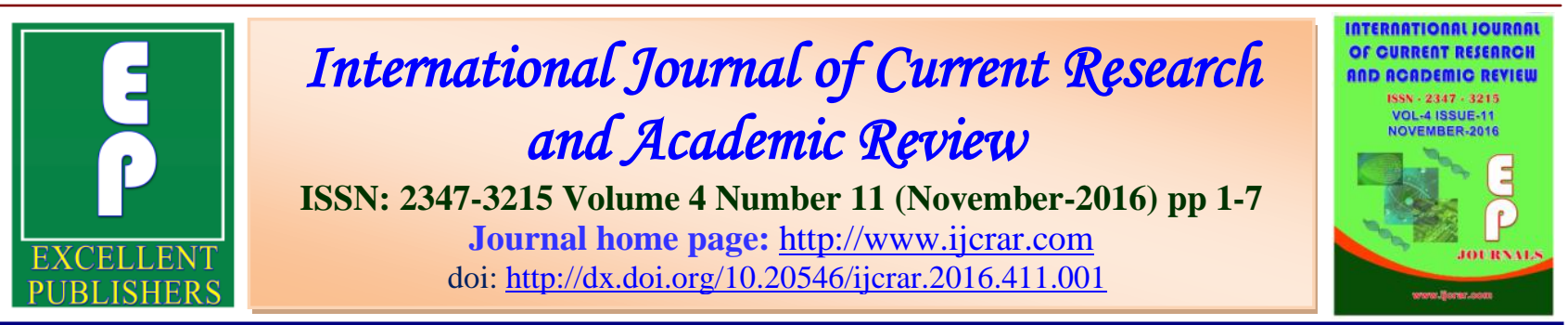

\title{
Structural Analysis of Jambur Oil Field using Different Techniques
}

\author{
Shaymaa Anwar Sadiq*, Faraj Ahmad Sulayman and Duraid Bahjat Deikran \\ University of Kirkuk, Kirkuk, Iraq \\ *Corresponding author
}

\begin{tabular}{l|l}
\multirow{2}{*}{$\begin{array}{l}\text { KEYWORDS } \\
\text { Dipmeter log, } \\
\text { fault, } \\
\text { formation. }\end{array}$} & $\begin{array}{l}\text { A B } \mathbf{S} \text { T R A } \mathbf{A} \text { T } \\
\text { The current study included a structural analysis of Jambur oil field using } \\
\text { dipmeter log technique to see what geological structures is under the surface. } \\
\text { Dipmeter log technique is used for the surface of Jeribe formation. The results } \\
\text { of the knowledge of the degree of inclination of reverse faults that affected } \\
\text { the Jambur fold Longitudinally and almost parallel to the axis of the fold } \\
\text { where the fold affected by two reverse faults trend in opposite directions, one } \\
\text { to the north-east direction and the other to south-west direction in addition to } \\
\text { knowing the fold engineering depending on the curvature of the fold } \\
\text { (anticline fold). The reverse movement on the levels of these faults gave } \\
\text { geological section a flower form so-called in the structural geology flower } \\
\text { structure. }\end{array}$
\end{tabular}

\section{Introduction}

Dipmeter logging is an accurate measure of the micro resistivity at different depths for the same layer. If the layer is tilted, and this is what happens on the flank of geological structure, the expression of that is through the logs, they are four recorded the same resistivity for the same layer with simple difference in the depth. The first log penetrates the layer at depth higher than the second log, the second higher than the third, and so on as a result of layers' inclination. And because these logging records the resistivity in a perpendicular path to the well and not by the measure of the layers inclination, the first record represents the virtual inclination of the layer which is adjusted according to a program to the real inclination of the layer by using the triangles mathematical relationship (Pythagorean theorem).

The main function of the dipmeter logging tool is measuring the values and inclination directions of the layers and sedimentary characteristics of such as levels of stratification, where most of the sediments is deposited mainly flat, and then subjected to the post-deposition stage which is either uplifting or down wrapping. This dip after uplifting stage is referred to as the structural dip know by an arrow in the data called Tadpole plot, which is a measurement of micro resistivity of the elements of the layers at calculated depths. These dip 
measurements reflect the structural elements such as folds, faults and unconformities (Chattopadhya and Ghosh, 2006). Whereas seismic sections provide more information and are used to determine the general direction of the geological structures Fig (1).

\section{Geography}

The study area is located within the geographical area of the province of Kirkuk in two parts. Taza Khurmatu located to the north-west of the region and Daquq is located to the south-west of it. The study area enclosed by the longitudes

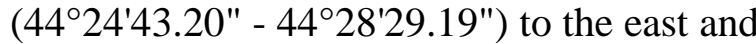
the latitudes $\left(35^{\circ} 25^{\prime} 51.94^{\prime \prime}-35^{\circ} 0^{\prime} 0.00\right.$ ") to the north Fig (2).

\section{Geology of the study area}

Tectonically, Jambur is located within Hemrin-Makhul Subzone extent according to (Buday \& Jassim, 1987) tectonic subdivisions return to the scope of which belongs to the bases of the mountains (within the unstable shelf). These extent folds are in the northwest- southwest direction. They are long folds characterized with flat tops forming anticline folds and broad concaves, in addition to the fact that its south-west wing is more inclined than its north-east wing and most of the southwestern wings affected by impulsive (inverse) faults.

Topographically, in the study area, sedimentary sequences which graduated in the age of the rocks from Miocene to Pliocene revealed in addition to the Quaternary sediments. It should be noted that it has been dealing with the upper top of the Jeribe formation in this study, and for this reason this part can be described as follows: consists of mass dolomitic limestone layers mutual with silicate limestone. limestone rocks are shaley neritic, fine crystals and dolomitic in some parts. The anhydrite exists through the region in the form of crumbs and intervenes to fill the voids (Naqib, 1960). Follows a description of these formations from the oldest to the newest: Fat'ha formation, Injana formation, and lower Bakhtiari Formation as well as the Quaternary deposits represented by foothills and the valley fill sediments Fig (3).

\section{Methodology}

The cross sections of the structural contour map for Jeribe formation are drawn and the available tops of the formations that penetrated by the wells in the field are reexamined according to the principles adopted for the drilled wells in the study area for the formations from Triassic and Cretaceous ages which are adopted by the current study as well as relying on the available dip-meter well $\operatorname{logs}$, studies and researches about the study area and the surrounding area, by Arc GIS V.10.2.

Four cross sections for the structure are drawn (their locations illustrated on Fig (4) The data used in drawing these geological sections are tops of strata values from wells records, dip-meter well logs and sometimes drilling reports following-up to determine the areas of losses in drilling fluid which are commonly used as indicators to the presence of faults, which were compatible with the locations of these faults in the sections that these faults strike the selected wells to draw the geological section.

The four geological sections that had been prepared Figs (5), (6), (7) and (8) show that the fold is asymmetrical, and strike a series of small faults in relation to the two reverse faults on both sides of the fold. 
Int.J.Curr.Res.Aca.Rev.2016; 4(11): 1-7

Fig.1 The seismic section for well (Ja-26) which cuts Jambur fold

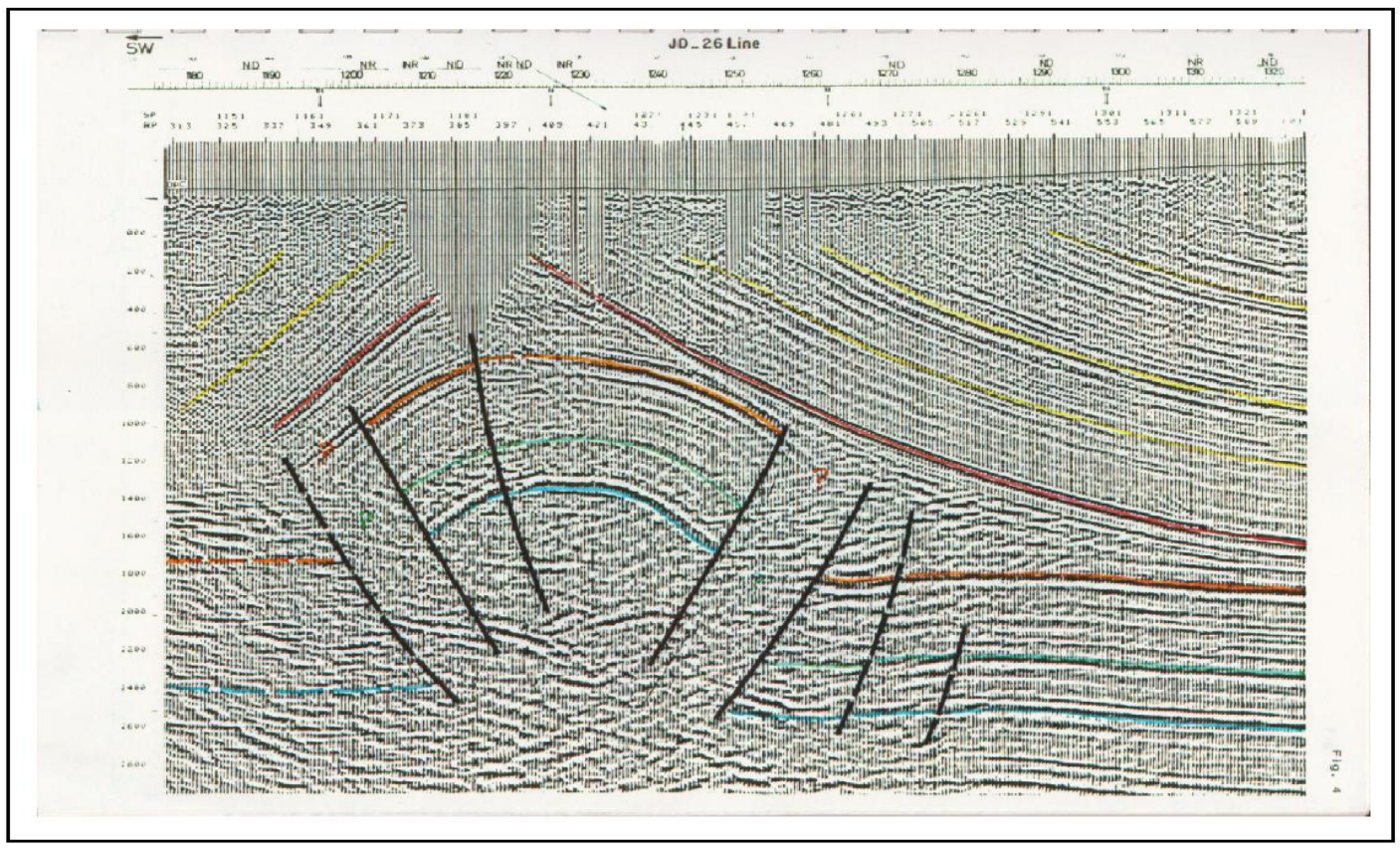

Fig.2 The location of the study area A) map of Iraq and the study area indicated on it B) satellite view from Landsat 8 indicating the study area

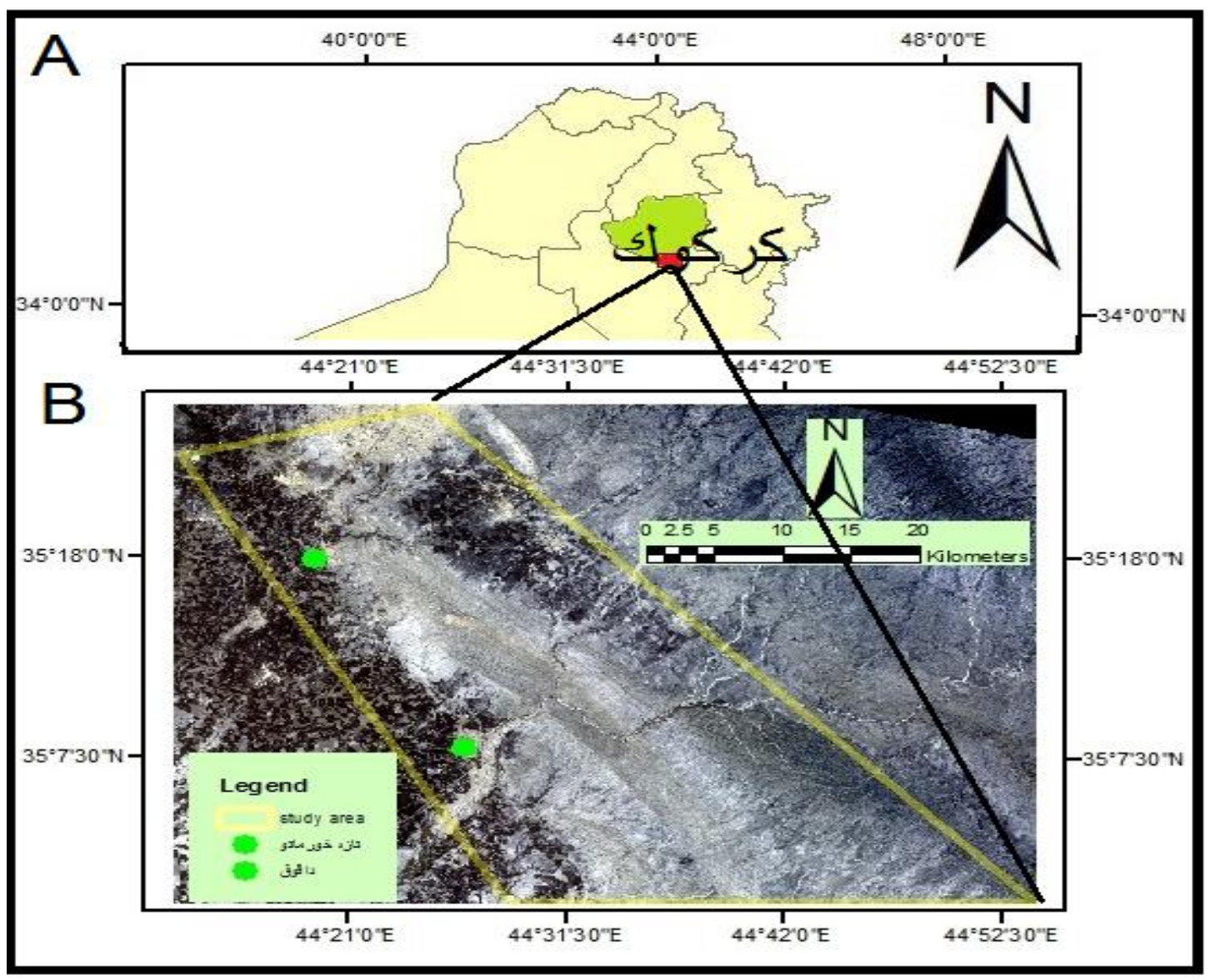


Int.J.Curr.Res.Aca.Rev.2016; 4(11): 1-7

Fig.3 A geological map of the study area (Revised Sissakian, 1993)

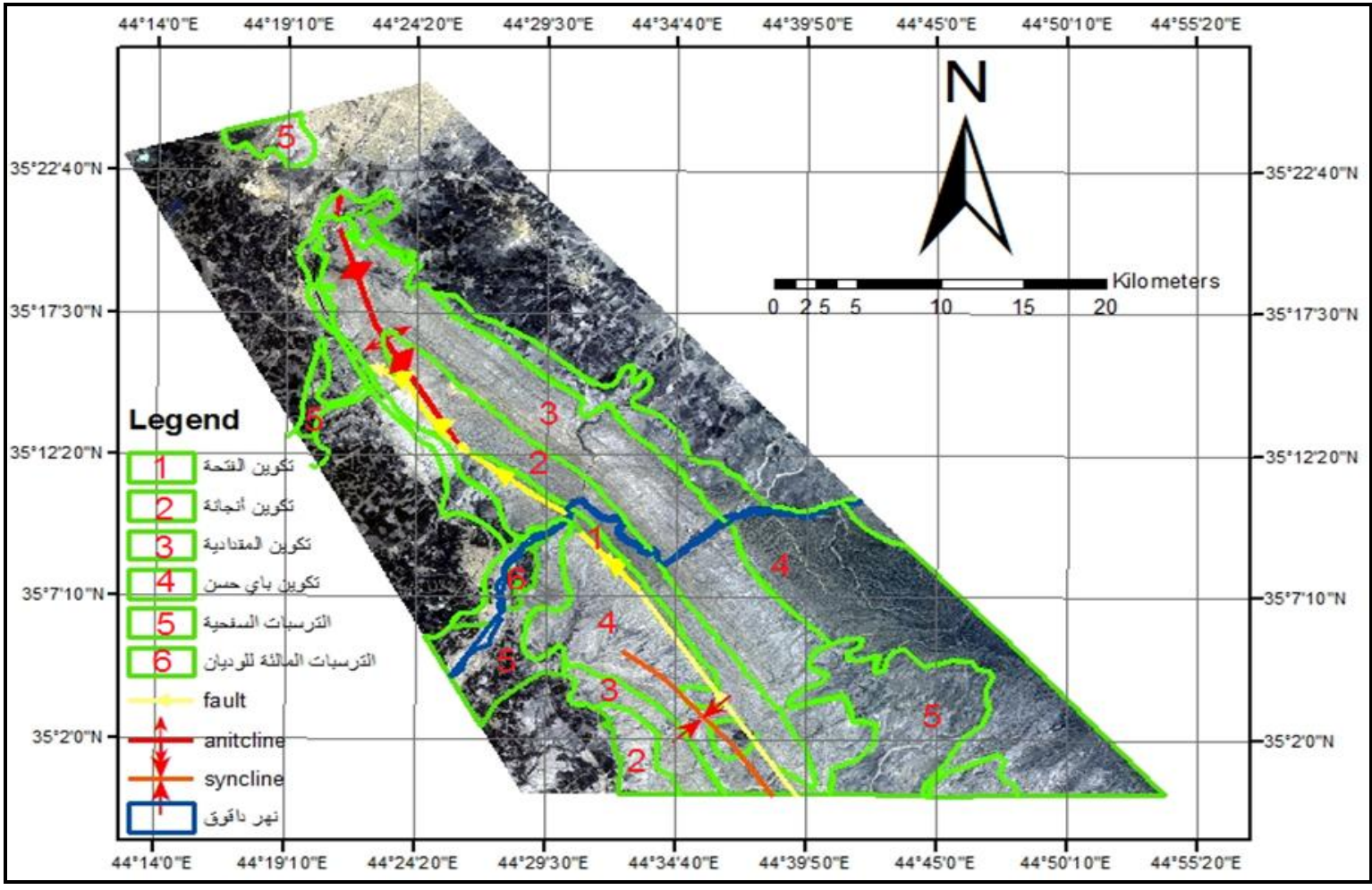

Fig.4 Structural map for top of Jeribe formation (North Oil Company), the cross

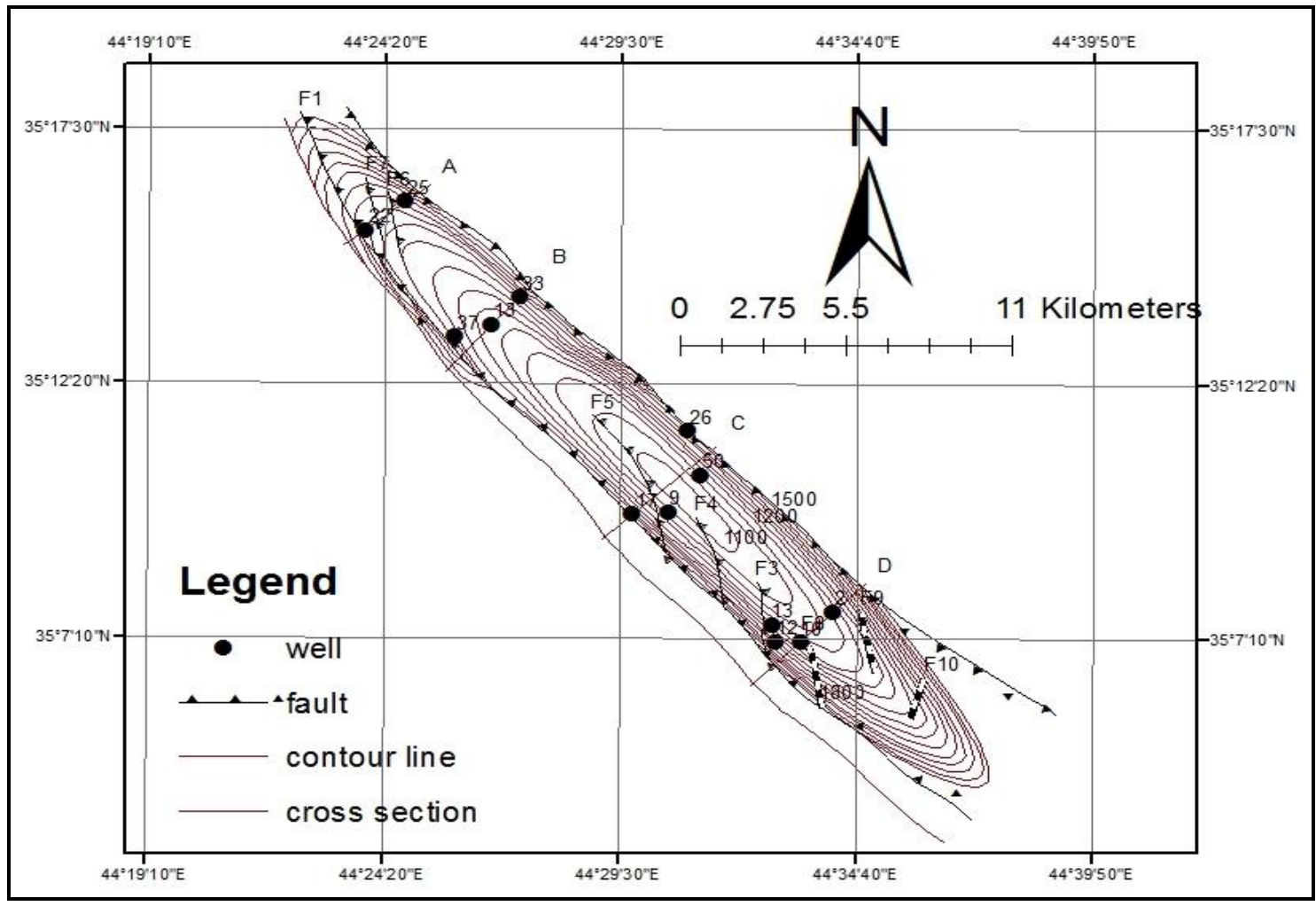


Int.J.Curr.Res.Aca.Rev.2016; 4(11): 1-7

Fig.5 Shows a cross-section passes wells (ja-22, ja-25)

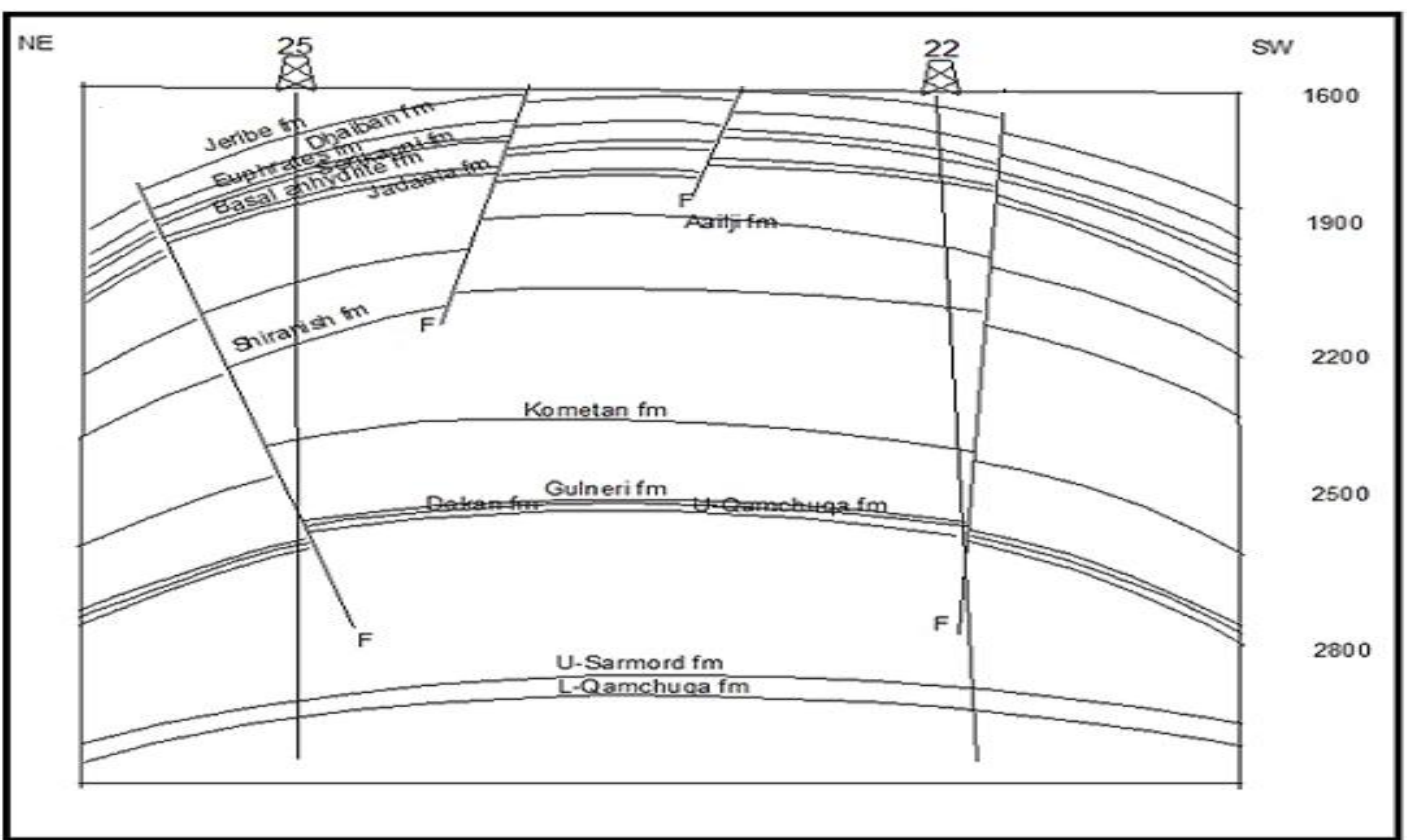

Fig.6 Shows a cross-section passes wells (ja-33, ja-13, ja-37)

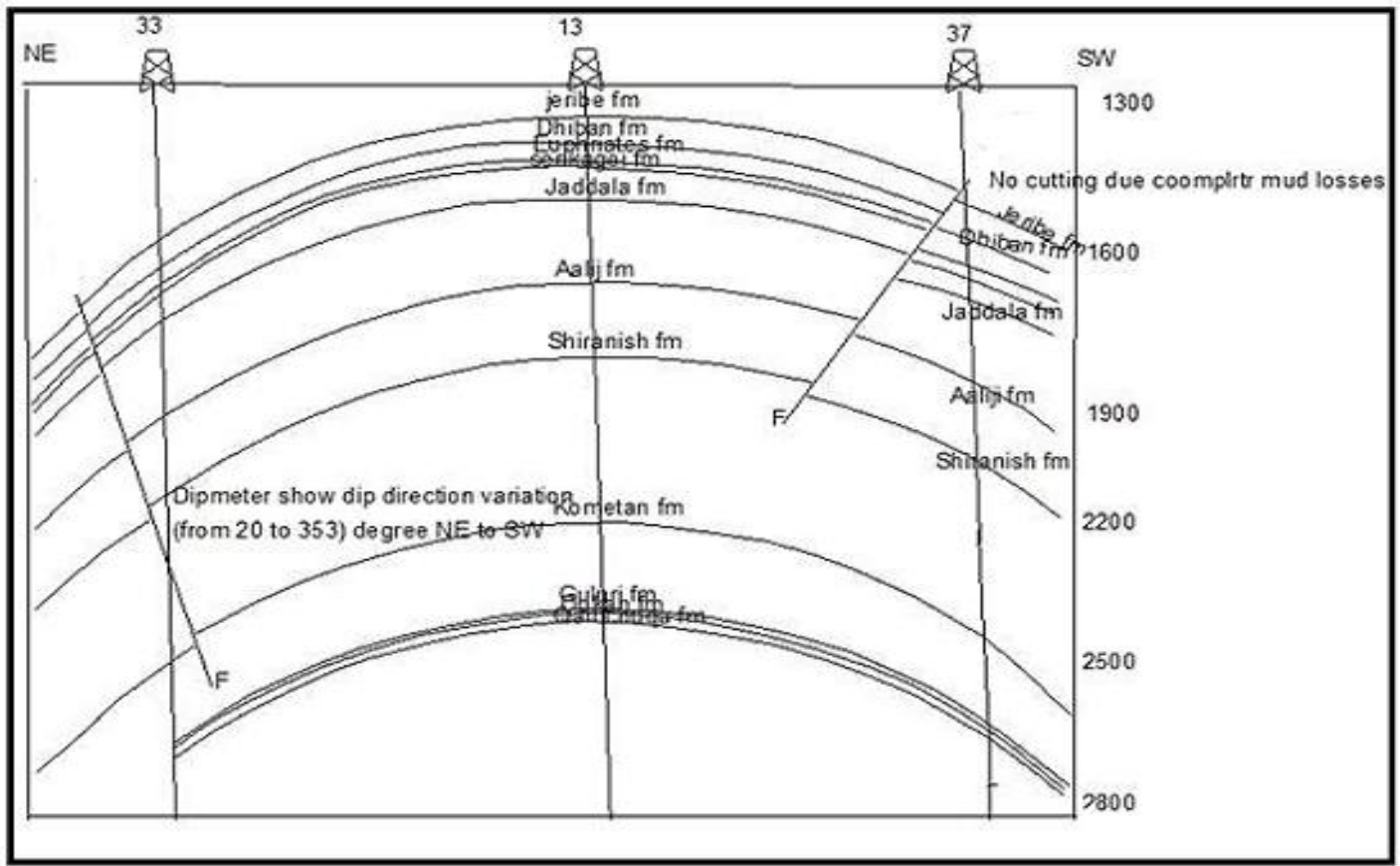


Fig.7 Shows a cross-section passes wells (ja-26, ja-50, ja-9, ja-17)

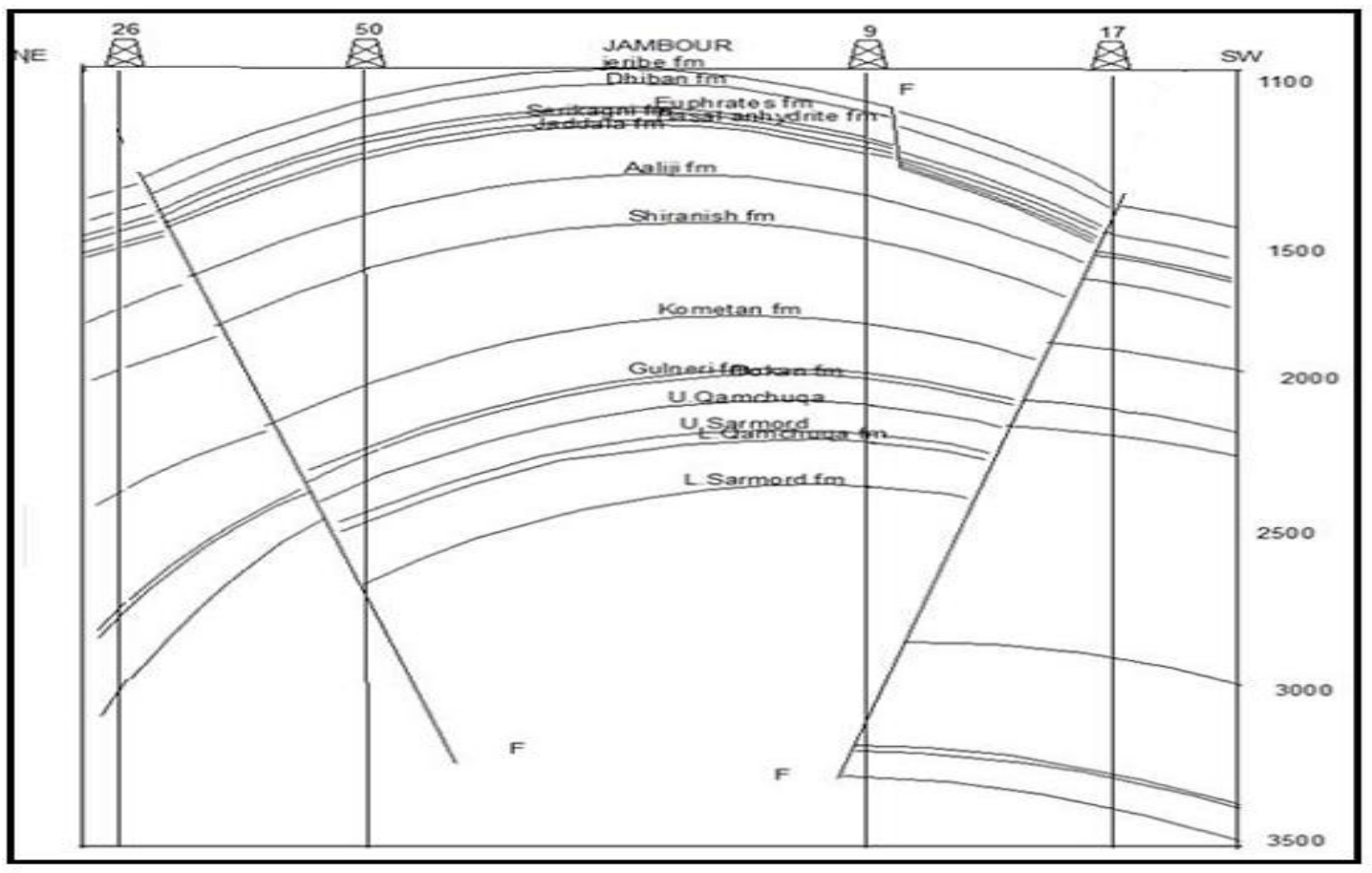

Fig.8 Shows a cross-section passes wells ((ja-2, ja-10, ja-12, ja-3

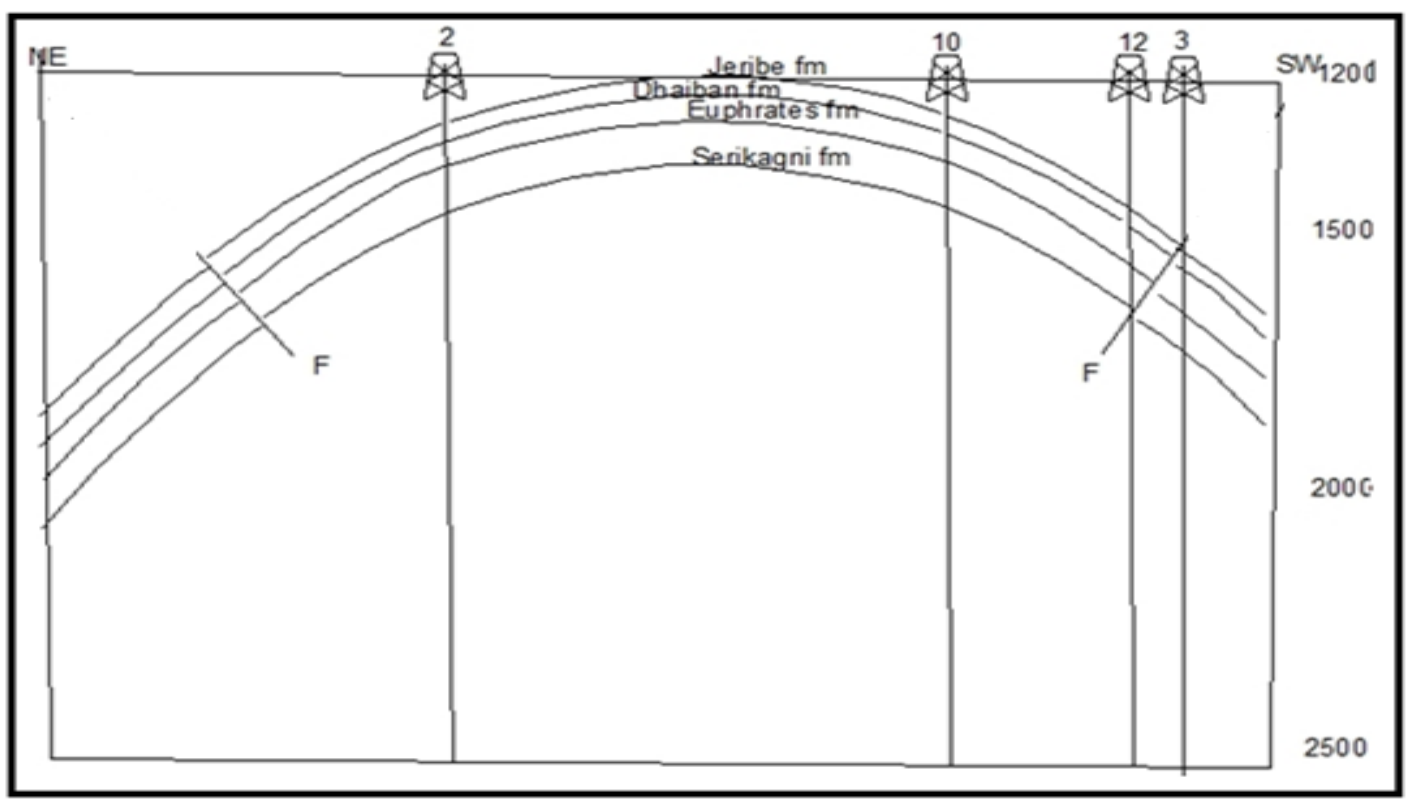

\section{Conclusion}

The degree of reverse faults dips observed from the cross sections, which affected the Jambur fold in a longitude direction and almost parallel to the fold axis where the fold affected by two reverse faults and dips in opposite directions, one toward the northeast and the other to the south-west, in addition to the knowledge of fold geometry 
depending on the direction of the curvature of the fold (anticline fold).

A comparison of the geological sections with one seismic section Fig (1) refers to the great similarities between them in terms of the pattern of movement and the structure axial uplifting, which enhances this assumption A study in the Institut Français du Pétroleum IFP (1986) possibilities in Cleep Thrust Fault The study also pointed to the possibility of formation of this structural style of the fold which represented by axial uplifting.

\section{References}

Al-Naqib. 1960. Geology of the southern area of the Kirkuk liwa. $2^{\text {nd }}$ Arab Petroleum Cong. Pub., London.

ArcMap, 1995-2013. ArcGis V.10.2, Applicable. Contracts and Legal Services Manager, Esri, 380 New York Street, Redlands, CA 923738100, USA ,www.esri.com.
Buday, T., and Jassim, S.Z. 1987. The Regional geology of Iraq, Vol. 2, Tectonism, Magmatism, and Metamorphism, Directorate of Geological Survey and Mineral Investigation, Baghdad, $352 \mathrm{p}$.

Bureau De studes Indusrielles Et De Cooperation De L institut France Du Petrole. 1986. Jambur structural model.

Chattopadhyay, T. and Ghosh, D.K. 2006. Structural Interpretation of Dipmeter Log - A Case Study from Baramura Field of Tripura, Petropysics Division, KDMIPE, ONGC, Dehradun India, 6th International Conference \& Exposition on Petroleum Geophysics "Kolkata 2006".

Schlumberger.

1980. Dipmeter Interpretation Fundamentals; Schlumberger, New York, USA.

Sissakian, V.K. 1993, Geological Mop of Kirkuk Quadrangle, SHEET NI-38-2, GEOSERV.

\section{How to cite this article:}

Shaymaa Anwar Sadiq, Faraj Ahmad Sulayman and Duraid Bahjat Deikran. 2016. Structural Analysis of Jambur Oil Field using Different Techniques. Int.J.Curr.Res.Aca.Rev.4(11):1-7. doi: http://dx.doi.org/10.20546/ijcrar.2016.411.001 